\title{
Effect of Honey a Natural Sweetener with Several Medicinal Properties on the Attributes of a Frozen Dessert Containing the Probiotic Lactobacillus acidophilus
}

\author{
Abigail Greenbaum ${ }^{1}$, Kayanush J. Aryana ${ }^{1,2^{*}}$ \\ ${ }^{1}$ School of Animal Science, Louisiana State University Agricultural Center, Baton Rouge, USA \\ ${ }^{2}$ Department of Food Science, Louisiana State University Agricultural Center, Baton Rouge, USA \\ Email: "karyana@agcenter.lsu.edu
}

Received August 12, 2012; revised September 13, 2012; accepted September 20, 2012

Copyright (C 2013 Abigail Greenbaum, Kayanush J. Aryana. This is an open access article distributed under the Creative Commons Attribution License, which permits unrestricted use, distribution, and reproduction in any medium, provided the original work is properly cited.

\begin{abstract}
Lactobacillus acidophilus has several health advantages. Honey has several medicinal properties and is also a natural sweetener which could be used in frozen desserts. There are various types of honey based on color namely, light, amber and dark. Influence of honey on attributes of a probiotic frozen dessert is not known. The objective was to study the effect of light, amber colored and dark honey on the Lactobacillus acidophilus counts and quality attributes of probiotic ice cream. Ice creams were manufactured with use of Lactobacillus acidophilus at $50 \mathrm{~g}$ of frozen culture concentrate per 7.75 liters of ice cream mix and with the use of light or amber or dark honey individually. Control had no honey and was sweetened with sugar. Use of honey increased Lactobacillus acidophilus counts and viscosity, while decreased $\mathrm{pH}$ and melt down volume. Light honey ice cream had flavor and appearance scores comparable to the control vanilla ice cream. Light honey can be recommended for the manufacturing Lactobacillus acidophilus probiotic ice creams thus having a frozen dessert with the health advantageous medicinal properties of honey.
\end{abstract}

Keywords: Probiotic; Health; Dessert; Honey

\section{Introduction}

In ancient times honey has been used for the treatment of a variety of illnesses such as gastric disturbances, ulcers, wounds and burns [1]. For these treatments honey has either been ingested or topically applied. Honey is reported to have antiseptic properties hence also used for fighting infections in wounds [2]. There are several reported mechanisms by which honey has antibacterial action namely, bee defensing-1, methylglyoxal (MGO), $\mathrm{H}_{2} \mathrm{O}_{2}$, osmotic effect and $\mathrm{pH}$ [3].

Honey is also reported to have antioxidants which reduce the damage done to the colon in colitis [4] and antioxidants play a big role in prevention of cancer and heart disease. Darker the honey more is the level of antioxidants. Based on color shades, there are three distinct types of honey, light, amber and dark. Honey has also been reported to increase the counts of probiotics namely bifidobacteria and lactobacilli in the colon [5].

Lactobacillus acidophilus is probiotic (good helpful)

*Corresponding author. bacterium with several health advantages. The health benefits of Lactobacillus acidophilus are as follows, assists in lowering cholesterol, reduces occurrence of diarrhea in humans (children and adults), provides immune support for infections or cancer, provides a healthy replacement of good bacteria in the intestinal tract following antibiotic therapy, improves the symptoms of lactose intolerance which is very important in dairy product consumption [6]. Antitumor effect of $L$. acidophilus was reported earlier [7]. Oral dietary supplements containing viable cells of $L$. acidophilus decreased azoreductase, $\beta$ glucuronidase, and nitroreductase, bacterial enzymes which catalyze conversion of procarcinogens to carcinogens. Anticarcinogenic effect of $L$. acidophilus may be due to direct removal of procarcinogens and activation of the body's immune system. Dietary supplementation with $L$. acidophilus decreases the number of colon cancer cells in rats in a dose dependent manner [8].

Ice cream is a very popular dairy dessert which is typically sweetened by sugar. If honey is used as a sweetening source in the manufacture of a probiotic ice cream, it 
is not known what effect honey would have on the characteristics of a healthier probiotic ice cream. The objective was to study the effect of light, amber colored and dark honey on the Lactobacillus acidophilus counts and quality attributes of probiotic ice cream.

\section{Materials and Methods}

\subsection{Ice Cream Manufacture}

Ice creams of vanilla flavor were manufactured according to Aryana et al., [9] and Aryana and Summers [10] with slight modification that sugar was replaced with honey and the probiotic bacterium Lactobacillus acidophiluswas incorporated into all pasteurized and cooled ice cream mixes at the rate of $50 \mathrm{~g}$ of frozen culture concentrate per 7.75 liters of ice cream mix. Treatments were light, amber colored and dark honeys which were randomly assigned to the experimental unit, the milk lot. The control had no honey and was sweetened with sugar. Product manufacture was replicated three times.

\subsection{Lactobacillus acidophilus Counts}

Enumerations were conducted according to Aryana et al., [11]. The MRS sorbitol agar was used. MRS base medium was made on a one liter basis without dextrose as follows. Proteose peptone \#3(United States Biological, Swampscott, MA), 10.0 g, 10.0 g of beef extract (Becton, Dickinson and Co., Sparks, MD), 5.0 g of yeast extract (Becton, Dickinson and Co., Sparks, MD), 1.0 g of polysorbate 80 (Tween 80) (Sigma-Aldrich Inc., St. Louis, MO), $2.0 \mathrm{~g}$ of ammonium citrate (Fisher Scientific, Fair Lawn, NJ), $5.0 \mathrm{~g}$ of sodium acetate, anhydrous (EMD Chemicals Inc., Gibbstown, NJ), $0.1 \mathrm{~g}$ of magnesium sulfate, anhydrous (EMD Chemicals Inc., Gibbstown, NJ), $0.05 \mathrm{~g}$ of manganese sulfate, monohydrate (SigmaAldrich Inc., St. Louis, MO), 2.0 g of dipotassium phosphate (Fisher Scientific, Fair Lawn, NJ), and $15.0 \mathrm{~g}$ of agar (EMD Chemicals Inc., Gibbstown, NJ) and diluting these ingredients to the appropriate proportion of $1 \mathrm{~L}$ with distilled water. This mixture was heated to boiling with agitation before autoclaving at $121^{\circ} \mathrm{C}$ for $15 \mathrm{~min}$. A $10 \%(\mathrm{w} / \mathrm{v})$ sorbitol (EMD Chemicals Inc., Gibbstown, NJ) solution was prepared and filtered sterilized with Nalgene Membrane Filter Units (Nalge Co., Rochester, $\mathrm{NY}$ ), and the appropriate amount of this solution was aseptically added to the MRS base medium to form a $10 \%$ sorbitol solution (final concentration of $1 \%$ sorbitol i.e. $1 \mathrm{~g}$ sorbitol in $100 \mathrm{~mL}$ of final medium) and $90 \%$ MRS base medium mixture immediately before pouring the plates. The appropriate dilutions of ice cream were made with $99 \mathrm{~mL}$ of sterilized peptone (or sterilized Butterfield buffer in pre-filled dilution bottles (Weber Scientific, Hamilton, NJ)). Petri dishes were placed in BBL GasPaks (BBL, Becton, Dickinson and Co., Cockeysville,
MD) and incubated anaerobically at $37^{\circ} \mathrm{C}$ for $72 \mathrm{~h}$. A Quebec Darkfield Colony Counter (Leica Inc., Buffalo, $\mathrm{NY}$ ) was used to assist in enumerating the colonies. Small, rough, brownish, dull, colonies of 0.1 to $0.5 \mathrm{~mm}$ in diameter were counted. Lactobacillus acidophilus pure culture was also plated on MRS-sorbitol agar alongside the samples for visual comparison of colony morphology. Three replications were conducted.

\section{3. $\mathrm{pH}$}

The $\mathrm{pH}$ was determined using an Orion $\mathrm{pH}$ meter model 250 A/610 (Fisher Scientific, Instruments, Pittsburgh, PA) calibrated using commercial pH 4.00 and 7.00 buffers (Fisher Scientific). The $\mathrm{pH}$ determinations of ice cream mixes were made at $8^{\circ} \mathrm{C}$. The $\mathrm{pH}$ determinations were in duplicate. Three replications were conducted

\subsection{Meltdown}

A $100 \mathrm{~g}$ scoop of ice cream was placed on a wire gauge (6 wires $/ \mathrm{cm}^{2}$ ) at $22 \mathrm{C}$. Melted ice cream drained from the gauge was collected in a graduated cylinder. The volume collected in first hour was recorded. Three replications were conducted.

\subsection{Apparent Viscosity}

Ice cream mix apparent viscosities were determined at $8^{\circ} \mathrm{C}$ using a Brookfield DV II+ viscometer (Brookfield Engineering Lab Inc, Stoughton, MA) with a helipath stand. An RV \#2 spindle was used at $50 \mathrm{rpm}$. The data were acquired using the Wingather software (Brookfield). A hundred data points were averaged per replication. Three replications were conducted.

\subsection{Sensory Evaluation}

Sensory evaluations were conducted by a seven member experienced panel on the ice creams coded with three digit random number codes. The official American Dairy Science Association Intercollegiate Dairy Products Evaluation Contest Score Card for flavor with a 10 point scale $(10=$ no criticism $)$ and for appearance with a 5 point scale $(5=$ no criticism) were used. Three replications were conducted.

\subsection{Statistical Analysis}

Data were analyzed by Analysis of Variance using the "Proc mixed" linear model procedure of SAS [12]. Means were separated using the least significant difference test. Significant differences were determined at $\alpha=$ 0.05 .

\section{Results and Discussion}

Counts of Lactobacillus acidophilus as influenced by the 
different types of honey are shown in Figure 1. The $L$. acidophilus counts of ice creams with honey were significantly higher than the control. The L. acidophilus counts with the honey were at least $10^{7} \mathrm{cfu} / \mathrm{mL}$ which is desirable for a probiotic to have the probiotic effect upon ingestion. The L. acidophilus counts with Amber and Dark honey were significantly higher than the Light honey. Honey is supposed to have an antimicrobial property because of its osmotic effect [13] as honey has low water activity. As regards to the composition of fluid milk, fluid milk has $87 \%$ water. This water contained in fluid milk used in ice cream manufacture may have resulted in the loss of the low water activity of honey hence no longer behaving as an antimicrobial, allowing $L$. acidophilus to grow.

The $\mathrm{pH}$ of ice cream mixes as influenced by the different types of honey are shown in Figure 2.

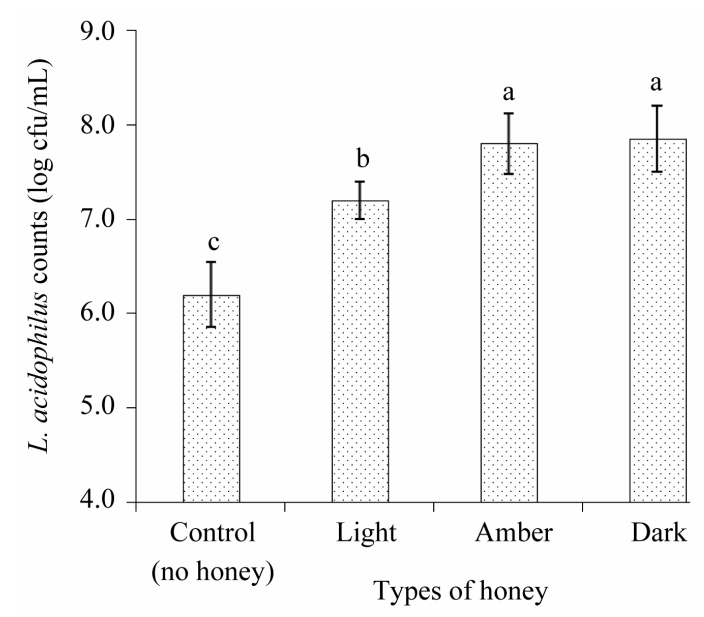

Figure 1. Counts of Lactobacillus acidophilus as influenced by the different types of honey.

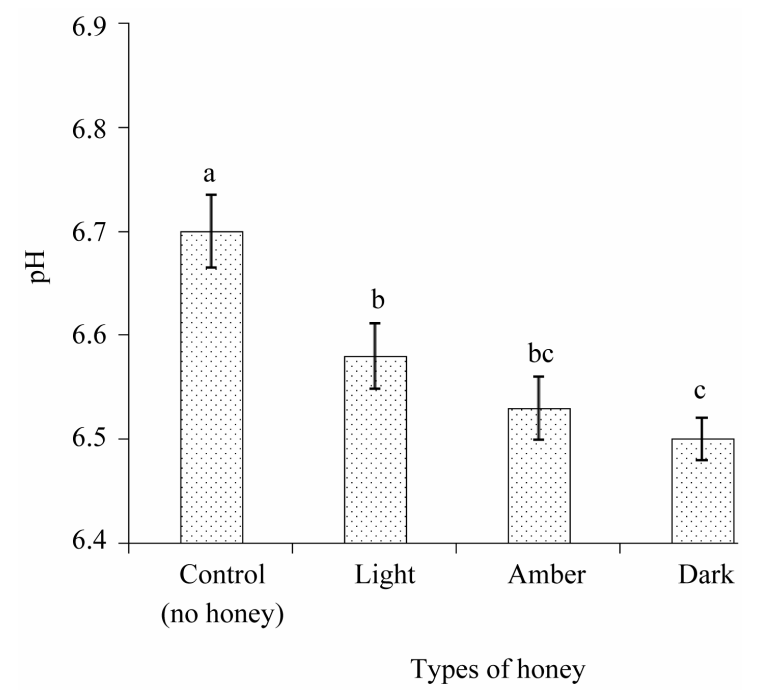

Figure 2. The pH of ice cream mixes as influenced by the different types of honey.
The control had significantly the highest $\mathrm{pH}$. Among the ice creams with honey, use of light honey resulted in significantly higher $\mathrm{pH}$ compared to dark honey. Honey usually has a pH between 3.2 - 4.5 [14] while fluid milk used to make ice cream had a $\mathrm{pH}$ of 6.8. Since there was no honey in the control to lower its $\mathrm{pH}$, the $\mathrm{pH}$ of the control was higher compared to the treatments. Also, low $\mathrm{pH}$ of honey is one of the factors for controlling microbial growth. Since the $\mathrm{pH}$ of the ice cream mixes were not as low as pure honey, it did not negatively influence the L. acidophilus counts keeping them in the desirable $10^{7} \mathrm{cfu}$ 's/mL (Figure 1).

Meltdown volumes in one hour of the various ice creams are shown in Figure 3. The ice creams with honey had significantly lower meltdown than the control. There were no significant differences in melt down among the light, amber or dark honey ice creams. Use of honey slowed the rate of meltdown which is desirable as consumers would not want their ice creams to melt rapidly.

Apparent viscosity values are shown in Figure 4. The control had significantly lower apparent viscosity compared to the ice creams with honey. Among the ice creams with honey there were no differences in apparent viscosity. Use of honey as a sweetener significantly increased the viscosity of the ice cream mixes. Honey is a viscous product and it imparted that viscosity to the ice cream mixes.

Flavor scores of ice creams made with different types of honey are shown in Figure 5. There were no differences in flavor of the control and the ice creams made using light and amber honey. While the ice cream made using the dark honey had significantly lower flavor scores perhaps because the dark honey had the strongest flavor compared to the other honies.

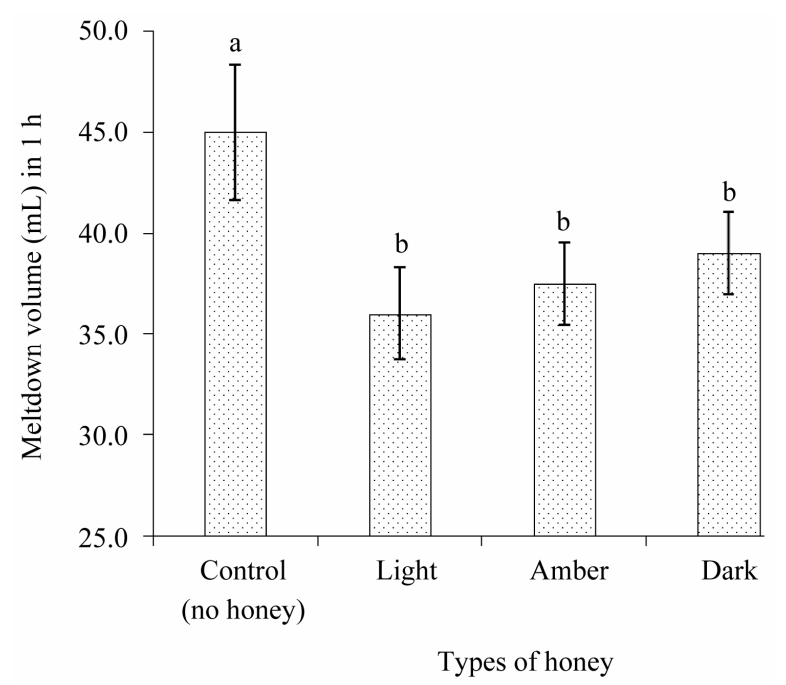

Figure 3. Meltdown volume in one hour of the ice creams made using different types of honey. 


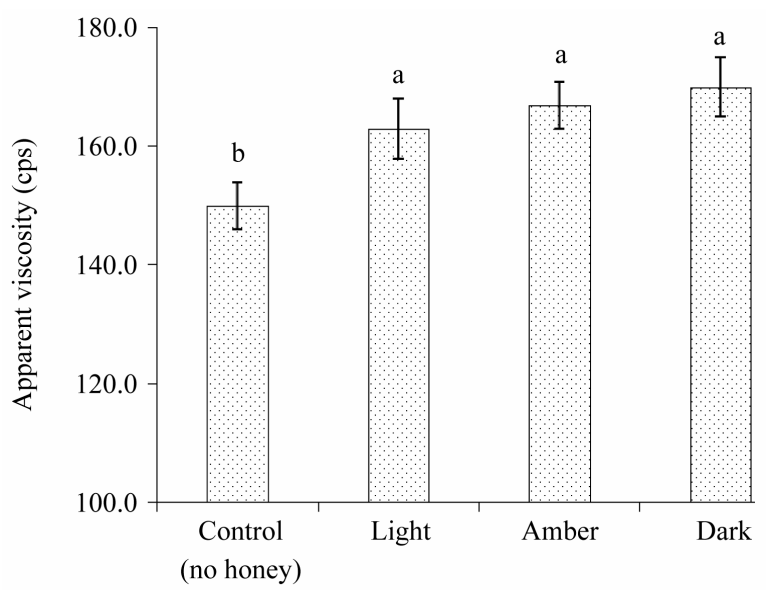

Types of honey

Figure 4. Apparent viscosity of the various ice cream mixesmade using different types of honey.

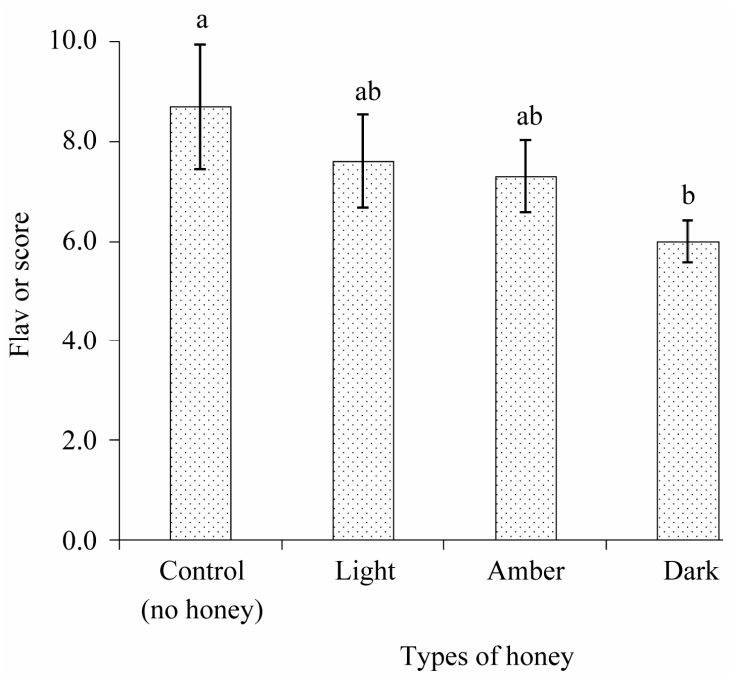

Figure 5. Flavor scores of ice creams made with different types of honey.

Appearance scores are shown in Figure 6. There were no differences in appearance among the control and the ice creams made with light honey. There were significantly lower scores with the use of Amber colored honey, while the use of the dark honey resulted in significantly the least scores. The dark color of the dark honey came through in the white vanilla ice cream making the vanilla ice creams off white, slightly greyish, which lowered the appearance scores.

\section{Conclusion}

Use of honey increased Lactobacillus acidophilus counts and viscosity, while decreased $\mathrm{pH}$ and melt down volume. Light honey ice cream had flavor and appearance scores comparable to the control vanilla ice cream. Light honey can be recommended for the manufacturing Lactobacil-

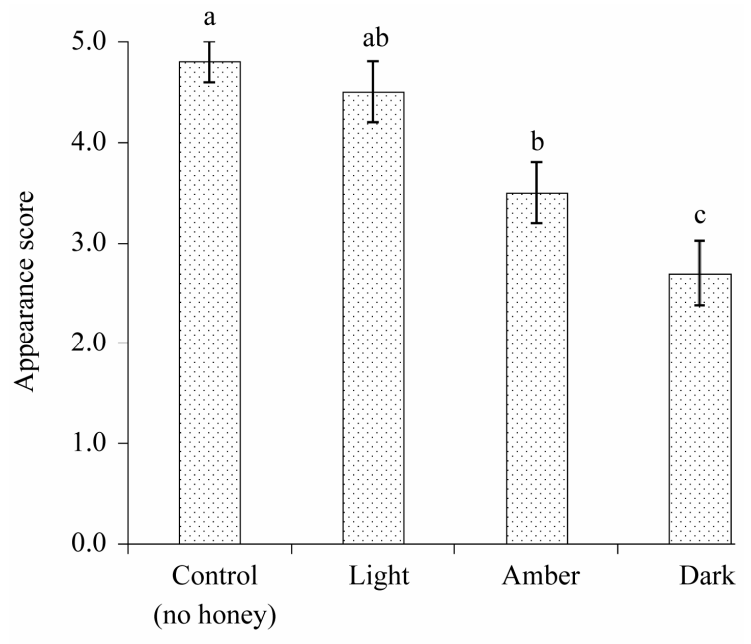

Types of honey

Figure 6. Appearance scores of ice creams made with different types of honey.

lus acidophilus probiotic ice creams thus having a frozen dessert with the health advantageous medicinal properties of honey.

\section{REFERENCES}

[1] P. C. Molan, "Honey for the Treatment of Infections," The New Zealand Beekeeper, Vol. 216, No. 1, 1992, pp. 19-20.

[2] L. B. Grotte, "Honey as a Dressing for Wounds, Burns and Ulcers: A Brief Review of Clinical Reports and Experimental Studies,” 2012. http://www.drgrotte.com/honey-medicine.shtml

[3] P. H. S. Kwakman, A. A. te Velde, L. Boer, D. Speijer, C. Vandenbroucke-Grauls and S. Zaat, "How Honey Kill Bacteria. Chapter 6 in Thrombocidins and Honey: Mechanisms of Action and Optimization of Antimicrobial Activity,” 2010. http://dare.uva.nl/document/175222

[4] Y. Bilsel, D. Bugra, S. Yamaner, T. Bulut, U. Cevikbas and U. Turkoglu, "Could Honey Have a Place in Colitis Therapy,” Digestive Surgery, Vol. 29, No. 4, 2002, pp. 306312. doi:10.1159/000064580

[5] A. M. E. El-Arab, S. M. Girgis, E. M. Hegazy and A. B. Abd El-Khalek, "Effect of Dietary Honey on Intestinal Microflora and Toxicity of Mycotoxins in Mice,” BMC Complementary and Alternative Medicine, BioMed Central Ltd., 2006.

http://www.biomedcentral.com/content/pdf/1472-6882-66.pdf

[6] M. E. Sanders, "Consideration for Use of Probiotic Bacteria to Modulate Human Health," Journal of Nutrition, Vol. 130, No. 2S, 2000, pp. 384S-390S.

[7] B. R. Goldin and S. L. Gorbach, “The Effect of Lactobacillus Feeding on Human Intestinal Bacterial Enzyme Activity," American Journal of Clinical Nutrition, Vol. 39, No. 5, 1984, pp. 756-761.

[8] C. V. Rao, M. E. Sanders, C. Indranie, B. Simi and B. S. 
Reddy, "Prevention of Colonic Preneoplastic Lesions by the Probiotic Lactobacillus acidophilus NCFMTM in F344 Rats,” International Journal of Oncology, Vol. 14, No. 5, 1999, pp. 939-944.

[9] K. J. Aryana, D. Olson, A. Greenbaum and C. Boeneke, "Quality Characteristics of a Weight Loss Ice Cream," Milk Science International, Vol. 63, No. 2, 2008, pp. 182185.

[10] K. J. Aryana and M. Summers, "Probiotic, Fat Free, No Sugar Added Ice-Cream,” Milk Science International, Vol. 61, No. 2, 2006, pp. 184-187.

[11] K. J. Aryana, S. Pluche, R. M. Rao, P. McGrew and N. P. Shah, "Fat-Free Plain Yogurt Manufactured with Inulins of Various Chain Lengths and Lactobacillus acidophillus,” Journal of Food Science, Vol. 72, No. 3, 2007, pp. M79-M84. doi:10.1111/j.1750-3841.2007.00302.X

[12] Statistical Analysis Systems, "SAS Version 9.1," SAS Institute Inc., Cary, 2002.

[13] P. E. Lusby, A. Coombes and J. M. Wilkinson, "Honey: A Potent Agent for Wound Healing?” Journal of Wound, Ostomy, and Continence Nursing: Official Publication of the Wound, Ostomy and Continence Nurses Society/WOCN, Vol. 29, No. 6, 2002, pp. 295-300.

[14] Waikato Honey Research Unit, "Honey as an Antimicrobial Agent," 2006.

http://bio.waikato.ac.nz/honey/honey_intro.shtml 